\title{
The Ghost of the Author and the Afterlife of Translation
}

Farheena Danta and Bijay K Danta

\begin{abstract}
This paper examines the politics that surrounds the translation of a text, especially the factors that go into the making of putatively canonical classics in translation. It argues that no translation is a faithful reproduction of an 'original' text in another language. Rather it shows how power relations, language hierarchies, political compulsions, cultural anxieties, ambiguous translation strategies, linguistic inadequacies, and misplaced notions of fidelity, among others, create an interesting trail that gives every translated text an interesting afterlife. Given that every act of translation is a translinguistic activity, it would be useful to examine how translated texts transcend their national and notional boundaries. The afterlife in the title refers to the involuntary network of which a text becomes part. Using the case of Phakir Mohan Senapati's Atmajivana, the authors argue that fidelity in translation has to be viewed not only in terms of the language from which one translates but also of the language to which one translates. Every translation has an afterlife that needs to be reckoned with.
\end{abstract}

This paper examines the relationship of authors to translators. While authors are likely to think of themselves as hosts and translators as parasites, to recall a famous formulation by J. Hillis Miller in a different but related context, the host-parasite register can neither explain nor reflect the situation correctly. The relationship changes in unexpected ways in different contexts of translation, depending on the nature and purpose of the translation. It would be interesting to see how the relationship is also bound by terms of affiliation, complicity, compliance, fidelity, betrayal, etc. already creating a divide between the "body" and its 
"excess." For instance when the "from-text" is less visible than the "to-text"(Ramanujan's words), the translator acquires considerable visibility, and sometimes demands as much critical attention as the author.

Lefevere and Bermann point out how translation is part of a larger social imperative which attempts (a) to make texts accessible and (b) to manipulate them in the service of a certain poetics and/or ideology. We will return to the implications of access and manipulation in translation, whether personal or professional. As well as a translinguistic activity, translation emerges as a social strategy. In fact, as Lefevere puts it, translation is "one of the strategies cultures develop to deal with what lies outside their boundaries and to maintain their own character while doing so - the kind of strategy that ultimately belongs in the realm of change and survival, not in dictionaries and grammars" (Lefevere, 2003: 10).

Here, one could possibly draw on Bhabha's famous nationnarration link, and recall Bermann's critique of the nationalist character of translations. It is our intention here to foreground the political premises of both writing and translation. As dealing with the vast body of scholarship and polemic that goes into the theses of Bhabha and Berman is bound to be distracting at this stage, we only expect to utilize their assumptions to arrive at a common hypothesis: given that writing is political, translation is bound to be political too.

Both Lefevere and Bermann concentrate on the politics and compulsions of translating alien texts into particular national languages. To this extent translation becomes a socially symbolic act, to use an expression by Fredric Jameson. The danger of distortion in such cases is high and any account of fidelity can be meaningfully discussed only in terms of the politics of choices and compulsions that may have led to bowdlerisations and alterations. In (post)colonial India, for example, there is ample evidence to show how translators acquired authority over the 
original producer of the text by translating political hierarchy into literary or linguistic hierarchy. In other words, colonization helped the translator to appropriate literary authority through political authority, allowing him to take liberties with the text without the author's permission or knowledge.

We would like to establish that ideas such as author and authority do not have a fixed meaning. As a matter of fact, what we call author (and by implication author or authority), is a complex network of images and associations ranging from book cover to rights and from book history to print types. In short the author is an elusive thing; rather than seeing the author as the undisputed producer of books and articles, we see the author also as a production of market requirements, national sentiments, and not infrequently academic or political opportunism. Once we accept this formulation, the role of the translator becomes even more interesting. In such a situation, the translator is neither the trustee nor the overseer of language transactions.

So what kind of space does the translator occupy? Is it the space granted to him by the author, by the project, or by the profession? Where does s/he belong? Is it along with the author, after the author, or before the author? Each is possible, and each has been a key to the translator's prestige and plight.

Is the translator bothered by the writer's authority, authorship, the unhappy reminder that $s /$ he is a worker in terms of manufacture or marketing capital goods, where the capital, and therefore, the authority rests with someone else? Is s/he required to play the catching up game ad infinitum, ad nauseum, and ad nihilum? In other words, can the translator speak when s/he is not expected to be anything other than an agent, a conveyor or carrier of meaning on behalf of somebody else or something else? If we further say that this somebody has the authority (that is the power) of authorship, authority (a government, administration, court, king or a powerful patron), institution, publisher, or even market expectation and packaging, the translator will always be 
looking over his/her shoulder for these ghosts. These ghosts are powerful when they are invisible to the naked eye, sickeningly present when they are supposed to be absent. Authors and authority can be authoritarian.

But who is an author? Is he the producer or the owner? Given that the author is seen as the arbiter of meaning and method, it would be instructive to look at alternative trajectories of authorship. We can draw on the plight of the author as producer, so powerfully articulated by Raymond Williams and Walter Benjamin. The author, or the artist-turned-artisan as they call him, not only has to part with his produce in a market economy but also produce what the market chooses for him. We are fascinated by the figure of this artist, this romantic artist alienated from art, and often want to restore the artist to his original position.

The word author is derived from the Latin word auctor/ augure (it could also be related to the word akshara) which means to produce or to increase. Interestingly, the nearest equivalent of the word in English is not writer but auctioneer (from the same root auctor), which means one who seeks out the highest bidder. Two other words with which the author claims kinship in the history of meaning (not equivalence) are writer and scribe. Both words have more to do with (writan or scrape) engraving or scratching as unruly children (or even creative adults), perhaps do on their writing desks. The maximum the history of the word may allow the writer to do is put pen to paper, scratch on the surface of the paper, or scribble (the Oriya word is gareiba, to draw lines from the word gara or line). Writing is in such company scribbling in an illegible manner. The authority of the writer as an ever present sentient being or transcendent subject has more to with the anxiety of the writer to something meaningful, something that will lift his profession. If we follow this trajectory we will see why and how New Criticism killed the author, which will release the text from its apparent owner, and allow the text to come into play.

Following on we may even see why Foucault said that 
the relationship between author and authority is critical. During the Middle Ages, the name of an author was important in the auctoritates, the auction place, where authority would be proof of identity, nothing else. The interesting part was that in case the translation was fake, the auctioneer can point to the producer. Any claim to authority was in a way the auctioneer's guarantee against incrimination and arrest for wrongdoing, or for bad or inaccurate copies.

It was more a sign of the author's helplessness than power, as we see it today. With the modern era, the conditions are reversed. A scientific text, in order to be truthful, must be anonymous. That is, a condition of its truthfulness is that it must be made up of statements which could have been proffered by anyone. The guarantee of their truthfulness lies in the quality of the demonstration.

In the seventeenth and eighteenth centuries, a totally new conception was developed when scientific texts were accepted on their own merits and positioned within an anonymous and coherent conceptual system of established truths and methods of verification. Authentication no longer required reference to the individual who had produced them; the role of the author disappeared as an index of truthfulness. (Foucault, 1977:126)

There are many other kinds of complexity which enter into the definition of authorship. For instance, is Nietzsche to be considered the "author" of laundry lists? Does authorship pertain only to texts or can it be extended to modes and systems of discourse, such as Marxism or psychoanalysis? The definition of authorship and the critical meaning which we attribute to the identity of the author have a lot to do with regimes of literary property, with the romanticized equation of authors with heroes, and with the terms which are used to evaluate literature. Our conceptions of authorship, despite the "death" of the author in twentieth century literature, have come from the renaissance construction of individualism and the romantic construction of 
subjective empowerment.

What of the translator, then? If we define translation today as referring to any kind of translinguistic activity, the translator is someone who transfers texts from one language to another, regardless of the type of text. But this is where the problem lies. The "poverty" of our understanding of translation and fidelity lies in its reliance on numerous sets of rigid binary oppositions which reciprocally validate one another. Translation is considered to be an act of re-production, through which the meaning of a text is transferred from one language to another. Each polar element in the translating process is construed as an absolute, and meaning is transposed from one pole to the other. But the fixity implied in the oppositions between languages, between original/copy, author/ translator, and, by analogy, male/female, cannot be absolute; these terms are rather to be placed on a continuum where each can be considered in relative terms. As Susan Bassnett points out, contemporary translation studies often runs into "the old binary concept of translation [which] saw original and translated text as two poles." It seeks to work with translation as a dynamic activity fully engaged with cultural systems (Bassnett, 2002:66). Barbara Godard emphasizes the ways in which this view of translation eliminates "cultural traces and self-reflexive elements," depriving the translated text of its "foundation in events." This is the only way to stop thinking of the "translator [as] a servant, an invisible hand mechanically turning the word of one language into another" (Godard, 1990:91). It is by destroying the absolutes of polarity that we can advance in our understanding of social and literary relations.

Attention must shift to those areas of identity where the indeterminate comes into play. Equivalence in translation, as contemporary translation theory emphasizes, cannot be a oneto-one proposition. The process of translation must be seen as a fluid production of meaning, similar to other kinds of writing. However, instead of perpetuating the hierarchy of writing roles, by reversing race or gender identities, translators can see themselves 
as part of a mobile and performative community. The interstitial may become the focus of investigation, and indeed a point to work with, once the polarized extremes are set aside. Because it is an activity which has long been theorized in terms of a hierarchy of class or gender positions, the rethinking of translation will necessarily upset traditional vocabularies of domination.

In particular, the rethinking of translation involves a widening of the definition of the translating subject. Who translates? Fidelity can only be understood if we take a new look at the identity of translating subjects and their enlarged area of responsibility as signatories of "doubly authored" documents. At the same time, a whole nexus of assumptions around issues of authority and agency come to be challenged. When meaning is no longer a hidden truth to be "discovered," but a set of discursive conditions to be "re-created," the work of the translator acquires added dimensions.

We are not sure that everybody agrees, but there is a point in what is suggested. Translations are productions, performances. We talk about Shakespeare's Hamlet and "hundred and six" performances, John Gielgud's 1947 classic or the Beijing University student guild's 1956 production where everybody wore the same college uniform, and there was no such thing like a boy or a girl doing the boy and the girl. Each has its own logic of production and if we believe Jan Kott, one of Shakespeare's most influential critics, the performances were blessed by Shakespeare's ghost. After all these performances, make Shakespeare their contemporary, making the Shakespeare text respond to their present. In spirit this is the role and responsibility of the translator. Lest we should be mistaken, this is not a plea of adaptation, which has its own place and worth, and which possibly has played a greater part in the transmission of culture than what we call translation today.

We would refer to two interesting cases here. The first one is the 1924 translation of Tagore's Gora (1909), by Macmillan, London, which ran fifteen reprints between 1924 and 1976. The 
book was reissued by Macmillan India in 1980, and was reprinted twice in 1993 and 1995. The book was presented by Macmillan as a translation but the name of the translator was not given. In the Indian editions, it was presented as part of a series that was called "Tagore in English," giving the impression that it was either translated by Tagore or worse still, it was a book written by Tagore in English. What is, however, more interesting is this kind of packaging. The 1924 English translation was apparently of the book published in 1909, which was at variance with the original magazine version serialized in Probashi.

It is true that the book that Tagore published had already excluded many portions from the magazine serializations. In 192223 , as the translation was being done by WW Pearson, one-time missionary and later teacher at Shantiniketan, Tagore said in a letter that he was not sure about the ability of the English reading public to see the importance of passages involving "scenes and sentiments which are foreign to them" (Mukherjee, 1981: 102). Tagore in fact proposed that once completed, the translation "will have to be carefully abridged" (102). Tagore's letter was not read by the addressee (Pearson), as he fell from a moving train in Italy and died. Pearson's translation was as reported by Tagore himself was read and revised by his nephew, Surendranath Tagore, but even as he had read not more than half the manuscript, Macmillan published the book. This book neither carried the abridgements that Tagore intended nor incorporated revisions of the entire text.

But this seemingly full-length book with inaccuracies was the only English translation of Gora in circulation till 1997 when Sahitya Akademi asked Sujit Mukherjee to translate the full version of the text. Incidentally the Bangla text had been corrected and restored from the magazine version in 1928 and 1941 respectively. Macmillan paid no heed to the fact that its translation of Gora was incomplete and inauthentic. More importantly, Tagore didn't seem to really worry much about the incomplete text and inauthentic translation. The fact that it gave him a presence in the English speaking world was more important at that stage. What we want 
to say here is that many of us have read only this version of the novel, and Tagore's international reputation as a novelist at least has been created by a text that was doubly flawed. In India, several translations of Gora have used this text of 1924. This already puts the relationship between authority and author-ity under the scanner. The Nobel Prize of 1912, and fact that Tagore was and continues to be the most widely known Indian writer abroad, hardly allowed the space to review the translation histories of his work. For people who read Tagore in translation only, there was no way to know that Tagore's finest novel was not even the novel that one was supposed to have read.

The second case relates to John Boulton's English translation of the Oriya novelist Phakir Mohan Senapti's Atmajivanacharita, the first autobiography in Oriya ${ }^{1}$. It is an exceptional book, important for its critique of British rule, which often bordered between the insane and the ludicrous, of the response of the new middleclass to the declining fortunes of Orissa, and for its portrayal of the death of a way of life. The book was translated into English as My Times and I by J V Boulton and published as part of Phakir Mohan Senapati: Life and Times (1969). In fact, Phakir Mohan's reputation outside Orissa (and possibly India), can be attributed to this book. In the translation, Boulton's disaffection with Phakir Mohan's historical ramblings on his family is immediately evident as he excises a sizable chunk of the text and provides a short summary of the portion thus excised. A peculiar practice throughout the translation is Boulton's unwillingness to explain why the cuts are made where they are made. Space does not seem to be a consideration as he provides commentaries along with the short summaries.

More than that, Boulton mixes his own summaries and commentaries with Phakir Mohan's text without any transparent indication, though bilingual readers who compare the two texts will find that Boulton has unfailingly indicated breaks in the text by providing asterisks between his text and Phakir Mohan's. For readers without access to the original, these asterisks do not serve 
the purpose for which they were put by Boulton. Again, more comparisons of the two texts reveal a pattern that cannot be ignored. While Boulton assiduously keeps to Phakir Mohan's text when he is very critical of the British, he avoids passages that in his reckoning would be offensive to the Bengali and Oriya readers.

It is now difficult to decide how much of this arrangement owed to Phakir Mohan's ambiguous response towards vernacular education imparted to Oriyas in undivided Bengal, left as it was to the itinerant teachers who were left to their own devices without any state policy. Moreover, in Phakir Mohan's text these men resembled cows let loose after Dol Purnima. Interestingly, this version of the book has been used by many Indian translators for their translations. While we do not have the evidence as yet, the Hindi translation may have been used by the others perpetuating the story of truncated authorship. The Assamese translation by Jayantimala Borpujari mostly follows the Boulton selections and excludes the passages not included in the latter.

The king inspected my body again and again, and with each scrutiny was more and more unimpressed. He saw I was wiry, and therefore emaciated, and therefore ugly and stupid. So he reached the conclusion that 'This new secretary is ugly and dumb. But since the person has been sent by the Superdant [sic] Sahib, he has to be made sound in the mind and good-looking, too.' So he arranged to send two seers of ghee for my daily consumption (Senapati, 1997).

We the inhabitants of Balasore must admit openly that we have acquired good conduct, fine bearings, and education, etc. from our association with the Bengali gentlemen. But, our own nature notwithstanding, I dare say that we have also acquired our alcoholism from these gentlemen.... Then all the Bengali officials posted at Balasore were alcoholics. I still remember the names of two or three Bengali teachers who never touched alcohol. I am talking of times when educated young men not exposed to drinking were treated with disdain by one and all. A young man 
teetotaller would normally buy and keep a little alcohol in a small glass bottle at home. Whenever he went out to the so-called high society, he used to rub a little alcohol in his whiskers and pretended to be drunk (Senapati, 1997).

Translation theorists have rightly pleaded for translation of sense rather than word order. This type of translation, which tries above all to save the spirit, also fails to keep the letter, but seems to go unnoticed even when it takes the greatest liberties. It is not a faithful copy of its original, but a second original in its own right. Bad translations, it is suggested, render the letter without the spirit in a low and servile imitation. Good translations, it follows, keep the spirit even when they seem to move away from the letter. But the question is: whose letter and whose spirit? As A. K. Ramanujan says:

To translate is to 'metaphor', to 'carry across'. Translations are transpositions, re-enactments, interpretations. Some elements of the original cannot be transposed at all. One can often convey a sense of the original rhythm. but not the language-bound metre: one can mimic levels of diction, but not the actual sound of the original words. Textures are harder (maybe impossible) to translate than structures, linear order more difficult than syntax, lines more difficult than larger patterns. Poetry is made at all these levels-and so is translation... The translation must not only represent, but re-present, the original. One walks a tightrope between the Tolanguage and the From-language, in a double loyalty. A translator is an 'artist on oath'. Sometimes one may succeed only in representing a poem, not in closely representing it. (Ramanujan, 1999: 23-31)

Writing, as Stephen Greenblatt says of Shakespeare's work, is the circulation of social energy. This circulation arrests the unilinear flow of state power and social authority by admitting exceptions to norms. Writing subverts social authority by circulating social energy in unexpected ways, and in unexpected quarters. Materialist critiques of power draw our attention to the 
similarity between hegemonic control over people and capitalistic hold on production, and the dangers of both.

In the translation scene, the authority of the author flows from what seems to be (a) the ownership of capital and (b) his refusal to part with his undisputed right over his property. In such a situation, the translator threatens to spoil the party by constantly trying to unsettle the author from his position, by releasing the text as it were from the author, or by creating conditions where such release would come without fail. Given the ferocity with which the author or authority would hold on to its terrain, the translator in his turn would interrupt the flow of power by inserting into the translation what we call "revisionary ratios" after Bloom. While it is possible to work with the six ratios proposed by Bloom, the translator may find only some of these more useful than the others. So the translator can challenge the author by returning the text to a moment prior to its birth, that is, by re-locating the text in its social circumstance of production, and not in its auctorial logic.

In so doing, the translator not only dislodges the author from his hierarchical position but also redefines authority outside the personal, often by highlighting the inconsequentiality of authorial intention. This is not a hypothetical position: in fact, every translator redefines his relation to the author of the source text while identifying the spirit of the work. This is not done through a customary declaration regarding obligations and responsibilities of the translator, but in the evidentiary choice of words, registers, setting of the translational universe. The choice or choices will specify whether the translator is willing to expose the "into text" to the violent uncertainties of the structures of the "from text."

In other words, the translator violates the social hierarchy of texts by admitting/coercing into already existing book histories/ literary traditions names, texts, and ideologies (some people prefer to call them values), that are alien to say the least. In the process the "into" language is compelled by the translator to 
forgo its assured look, and shed some of its grammatical markers, features, and compulsions.

We have been talking about the similarity in status of critics and translators. However, authors have learnt to be more tolerant towards critics than translators, realizing that books discussed by academic critics, often run into multiple editions and can rekindle the dying embers of reputations and sales. It is possible that the author, who has already invested in a particular interpretive universe in the process of writing, expects the translator to reproduce the same in another language. There is no reason for him to expect the translator, in all fairness, to contribute anything to the process except by way of inter-language transport service, almost like a mover of goods. He is sure of his work and its meaning, and rules out critical intervention or difference. If this figuration sounds a little comic, the expectation that the translator carry the author's load faithfully and deliver it to the reader in good faith suggests how the author would want the translator to be an authorized transporter of goods, and nothing else.

The translator has his say/revenge by giving the author an afterlife. Some may think of this as a reward, a recognition, an acknowledgement not of authority but of affection, or of an opportunity (for getting fame, money, visibility). In any case translation is a search for authority, a search for what Derrida calls not the perfect but the possible.

\section{NOTES}

Fakir Mohan Senapati is now spelt Phakir Mohan Senapti, the same way as the author signed his name. Though the autobiography has been variously called Atmajivana and Atmajivanacharita, editors like Debedra K Dash increasingly advocate the former. 


\section{REFERENCES}

Bassnett, Susan, 1980/2002. Translation Studies, New York: Routledge, 3rd rev. edn.

Benjamin, Walter, 1969. "The Task of the Translator." In Illuminations. Trans. H. Zohn, ed.H. Arendt. New York: Schocken Books.

Bermann, Sandra, and Michael Wood, eds. 2005. Nation, Language, and the Ethics of Translation, Princeton: Princeton University Press.

Bhabha, Homi K, ed. 1990. Nation and Narration, London: Routledge.

Derrida, Jacques. 1985. "Roundtable on Translation." In The Ear of the Other:Otobiography, Transference, Translation. Ed. Christie V. McDonald. Trans. Peggy Kamuf. New Yourk: Schocken Books: 98-110.

Foucault, Michel. Foucault, M. 1977. "What Is an Author?", In Language, Counter-Memory, Practice. Ed. D. Bouchard. Trans. D. Bouchard and S. Simon. Ithaca: Cornell University Press.

Godard, Barbara. 1990. "Theorizing Feminist Discourse/ Translation", In Translation.History and Culture. Ed. Susan Basnett and André Lefevere. London: FrancesPinter: 87-96.

Jameson, Fredric. 1981. The Political Unconscious: Narrative as a Socially Symbolic Act. Ithaca: Cornell University Press

Lefevere, Andre, ed. 2003. Translation/History/Culture: A Sourcebook. London: Routledge.

Miller, J Hillis. 1977. "Limits of Pluralism III: The Critic as Host", Critical Inquiry 3.3: 43947.

Mukherjee, Sujit. 1981. Translation as Discovery and Other Essays on Indian Literature in English Translation. New Delhi: Allied Publishers. 
Ramanujan, AK. 1999. On Translating a Tamil Poem."In The Collected Essays of A.K. Ramanujan. Ed. Vinay Dhrawadker. New York: Oxford University Press: 217-31.

Senapati, Phakir Mohan. 1997. Atmajivani. Assamese Trans. Jayantimala Borpijari. National Book Trust New Delhi.

Senapati, Phakir Mohan. 1997. Story of My Life. Trans. J. K. Nayak and P. Das. Bhubaneswar: Sateertha Publications.

Senapati, Phakir Mohan.1985. My Times and I. Trans. J. Boulton. Bhubaneswar: OrissaSahitya Akademi.

Williams, Raymond, 1958/1960. Culture and Society, New York: Doubleday. 